\title{
Electrolux refrigerator brand maintains freshness and antioxidant nutrient contents of selected vegetables and fruit better than other brands
}

\author{
Nutri Virtual Symposium 2020 \\ Nutrition Battling on Pandemic COVID-19: How to Survive
}

Link to DOI: $10.25220 /$ WNJ.V04.S3.0025

Journal Website: www.worldnutrijournal.org

Luciana B Sutanto ${ }^{1}$, Ani Retno Prijanti ${ }^{2}$, Helena Fabiani ${ }^{3}$, Novi Silvia Hardiany ${ }^{2}$, Febriana Catur Iswanti ${ }^{2}$, and Saptawati Bardosono ${ }^{3}$

${ }^{1}$ Faculty of Medicine, Universitas UKRIDA, Jakarta, Indonesia; Indonesian Nutrition Association, Jakarta, Indonesia

${ }^{2}$ Department of Biochemistry and Biomolecular, Faculty of Medicine, Universitas Indonesia, Jakarta, Indonesia

${ }^{3}$ Department of Nutrition, Faculty of Medicine, Universitas Indonesia, Jakarta, Indonesia

The aim of this study was to compare Electrolux refrigerator brand in maintaining freshness and antioxidant-nutrient contents of selected vegetables and fruit during the period of three weeks compare to other brands $(B \AA, C \AA$ and $D \circledR)$. This study was randomized controlled trial, held in Jakarta in August-November 2019. We used celeries, mushrooms and strawberries as samples that were stored in the crisper of four different brands of refrigerators for three weeks. All refrigerators were set at $8^{0} \mathrm{C}$. Data collected were freshness, vitamin $\mathrm{C}$, vitamin $\mathrm{E}$, fiber contents and antioxidant property at day $0,3,6,9,12,15,18$, and 21 . Freshness assessed using visual analogue scale, vitamin $\mathrm{C}$ and $\mathrm{E}$ levels measured using colorimetric assay, antioxidant property and total dietary fiber measured using total antioxidant capacity and fiber content assay kit.

Repeated measurements using general-linear model was done to analyze the difference among four refrigerator brands. The result of this study showed Electrolux brand maintained overall freshness of celeries and strawberries for two weeks, and mushrooms for one week, while other three brands maintained shorter. These results were also seen for vitamin C, E and antioxidant properties. Conclusion: Electrolux refrigerator brand maintains freshness and antioxidant nutrient contents of selected vegetables and fruit better than other three brands.

Keywords: freshness, refrigeration, vitamin C, vitamin E, antioxidant, fiber

The study of this abstract was published in Journal of Food and Nutrition Research, 2020, Vol. 8, No. 6, 252-257, title "Effectivity of Various Refrigerator Brands in Maintaining Freshness and Antioxidant Nutrient Contents of Selected Vegetables and Fruit."

Link : http://www.sciepub.com/jfnr/abstract/12041

Journal of Food and Nutrition Research. 2020, 8(6), 252-257

DOI: $10.12691 / \mathrm{jfnr}-8-6-2$

\section{Corresponding author:}

Dr. dr. Luciana B Sutanto, MS, SpGK

Indonesian Nutrition Association, Jakarta, Indonesia

E-mail address: 1csutanto@yahoo.com 